\title{
BUILDING AND DEVELOPING THE NIGERIAN NATION THE ROLE OF POSITIVE SOCIAL SCIENCE
}

\section{P. DIEJOMAOH \\ N1SER, Ibadan.}

The critical importance of the role of the Social Sciences in National development has been recognised by several scholars for a long time ${ }^{1}$ now. In Nigeria itself the importance of the Social Sciences has partly been manifested by the rapid expansion of student enrolments in the Nigerian Universities. ${ }^{2}$ In spite of the above, there seems to be a growing disillusionment with the Social Sciences in Nigeria. There is a feeling that the Social Sciences have over-expanded in a quantitative sense, and many Social Science Faculties in Nigerian Universities are facing a cutback in student enrolment There are also some serious questions being raised about the content and quality of the Social Science curricula and research, and their general orientation and relevance. This Assembly will address some of these issues in the next two days. However, I feel it important, if not so much for the scholastic community but for the generality of the public and policy makers, in particular, that the critical role of the Social Sciences in national development be categorically restated and emphasised, so that the Social Sciences will get the national attention they deserve.

Although there is an increasing enchantment with Science and Technology today, it must be stressed that the overall pace of national development depends more critically on what is happening in the Social Sciences, for in many respects, the pace of advance in science and technology, and the implication of the results of scientific and technological research depend on the effective orientation of the Social Sciences.

The Social Sciences are responsible for the production of the manpower which controls the critical leadership posts in government, business and the rest of the private sector. Values, attitudes, and the general orientation of the society which are part of the nation's culture, and which determine in large measure the achievement of any people, are subjects for analysis in the Social Sciences. Most analysts have now come to the conclusion, for example, that the crisis of ineffective leadership is the greatest impediment to the future development of the Nigerian nation. Since part of the problem of past ineffective leadership in all segments of the Nigerian nation, has been the

'Presidential Address, 1985 
result of thief poor attitude and sense of value, we can all begin to see that unless proper attention is paid to the healthy development of the Social Sciences, the nation's development is likely to remain stunted for a long time. Developments in the economy, public policy, general orientation and welfare of the populace are heavily dependent in all nations on the strength, nature and character of the Social Sciences in such nations.

Perceptions of the State of Development in Nigeria: the Contribution of the Social Scientists

Since the primary preoccupation of the Social Science Council of Nigeria is the acceleration of the pace of national development in Nigeria, it is instructive as a first step to assess how we perceive the state of development of the nation; ?or the prospects for future development will heavily depend on that perception. The perception of the state of development in Nigeria has, of course, varied over the years but there has been a measure of continuity in that perception. Let me trace in outline my own summation of the national perception of the state of development of the Nigerian nation.

During the colonial era, the colonial administration and its supporting agencies, as well as religious institutions, succeeded in inculcating in Nigerians that the country was extremely backward, and its socio-cultural institutions particularly in southern Nigerian needed to be dismantled and replaced with a British or European model The conviction of Nigerians that they were backward was brought about by the ideas propagated to them through the works of British Social Scientists at the time. This conviction about their backwardness and inferiority, led Nigerians in the main to accept a position of subordination imposed by the British, with the result that Nigeria stagnated by and large during almost one hundred years of colonial rule. The post second World-War period up to our independence in 1960 was generally a period of hope ${ }^{1}$ that Nigeria could and should develop. This optimistic outlook with all its ramifications contributed in no small way to the significant pace of development that was actually achieved in that period. The contribution of the Social Scientists to development in this period was evident in the change of heart of Western Social Scientists, which led to their advocacy of the point of view that development was possible and desirable. This led to the massive spate of literature on development in the 1945-1960 period. Because of the limited supply of social scientists in Nigeria in the 19451960 period, the Social Sciences which held sway in Nigeria during that period was the optimistic Social Science of the Western scholars.

In the decade of the 1960s, the supply of Nigerian Social Scientists began to increase considerably. Concern began to mount on how to share the fruits of the development of the 1945 - 1960 period, and the future development that was envisaged in the 1960s and beyond. It is well documented now that considerable disagreements existed in that decade, partly fuelled by social 
scientists in the Universities. As a result of the disagreements which culminated in the civil war, and its associated destruction, the decade of the 1960s was overall for the nation, a decade of stagnation since whatever gains that were achieved in the first half of the 1960's were wiped out in the second half of the 1960s. The disagreements of the 1960s could be conceived of in a more positive sense, if it is argued that as a result of the disagreements and civil war, we were able to build a more stable federation, where the centre was strengthened at the expense of the regions or states, thereby providing a guarantee against future centrifugal tendencies. As a counter argument against the above, however, it can be contended that the achieved results could have been obtained at less cost than we actually paid, if appropriate anticipatory and preventive measures had been taken.

The decade of the 1970s was the decade of the oil boom. The GDP increased at an annual rate of about $8 \%$ between 1970 and 1979. The decade of the 1970's was perceived to be a decade of prosperity. Nigerians, both leaders and the public, conceived of Nigeria as a wealthy country, almost as if it was in fact a developed country., Even Social Scientists, including some economists, came to push and share the above view. But careful analysis did show that the perception of our state of development in that decade was false. ${ }^{5}$ The perception of Nigeria as a wealthy, almost developed country led to a number of disastrous policy decisions by practicing Social Scientists often with the support of academic social scientists. While there was a welcome increase in Our selfconfidence as a people during this decade, that self confidence was to a large extent misplaced and based on complacency.

We entered into the decade of the 1980s to witness the worst economic recession, in Nigeria and the World at large, since the Great depression of the 1930s. Gross Domestic product per capita declined by almost 20\% between 1980 and 1983. This substantial average decline in living standards had been exacerbated by the excesses of the political class, so that for the average income earner, the decline in living standards was cheaper than the $20 \%$ national average, probably reaching in about $50 \%$ decline. This sharp decline in living standards has, not unpredictably, led to a general feeling of pessimism about the state of and prospects for development in Nigeria. Some segments of the mass media and some academic Social Scientists have contributed to propagating a viewpoint that there is no hope for the Nigerian economy, and that future development prospects are bleak, to non-existent This dooms day scenario of the Nigerian nation is being shared by some youths even at secondary school level A great deal of skepticism and pessimism about the nation are emerging, while hopelessness is on the increase. Socio-economic analysis of conditions in the world during the Great Depression of the 1930s showed that similar expressions of despondency were common at the time. Yet the world economy was able to emerge from the Great Depression of the 
1930's stronger, and to embark on unprecedented high rate of uninterrupted economic growth and development for the quarter century between 1945 and 1970. Even the somewhat difficult decade of the 1970s for non-oil exporters still saw some significant development gains for a large number of countries.

The implication of the above analysis is that there is great danger in limiting social science, analysis to short-and-medium-term perspectives and in projecting the immediate and current state of development into the future. This type of perception leads to thinking that booms will last forever, while we shall never be able to get out of the trap of economic recessions or depressions. Such perceptions, of course, lead to wrong policy decisions and conclusions. Some Nigerian social scientists both practising and academic particularly the news media have tended to lead Nigerians into those mistaken paths with adverse implications for Nigeria's future development.

The Place of a Positive Social Science in National Development

Closely related to the issue of our perception of the state of our development is the manner in which Nigeria is portrayed to Nigerians and the outside world by Nigerians. The portrayal of Nigeria and Nigerians by Nigerians is partly a function of the state of knowledge in Nigerian Social Sciences and partly a function of the extent of our dependence on foreign social science analysis for our own world view and our view of our country. Given the openness of our system, the foreign views compete very favourably with our own indigenous appraisals of our own system. Judging from the writings about Nigeria in Nigeria's mass media, and the work of some serious local social science analysts and some general writers, the image of Nigeria is made out to be a Very negative one. Our intention is not to obscure the fact that Nigeria still has very serious outstanding problems. The identification and analysis of our social and economic problems is the very raison d'etre of the social sciences.

However, while engaging in problem analysis, it is also the function of social scientists to engage in the identification and propagation of the achievements and the positive aspects of our socio-economic systems. It is a common fact that in the Western nations there is a very strong and concerted effort to portray the western capitalist democratic system in the best possible light All their citizens, of all ages through their education system, publish information as transmitted through the mass media, meseums, national monuments, institutions of national heroes and the like, are led to having a very strong positive image of their society. Social Scientists alongside "with others play a very leading role in providing the information which helps in building this very positive image of the society. That a positive image of the socio-economic system is presented does not preclude self-criticism and analysis of problems. We all know that the Western nations have also built 


\section{Building and Developing The Nigerian Nation' The Role of a Positive Social Science}

into their system, this habit of self-criticism and innovative approaches to the solutions of their problems. Through a mix of self-confidence in their system and themselves, their socio-economic systems have been able to make steady and sustained progress, and widespread development has been achieved.

What has been said about the Western nations can equally be advanced for the socialist countries. The socialist countries have developed approaches similar to those of the Western nations and succeeded in presenting to their citizens a strong and positive image of their socio-economic system. They too realise that their system has problems which have to be kept under constant analysis and debate in the search for new and more effective solutions. As a result of the confidence the people have in themselves, and with their problem-solving attitude, they have been able to make remarkable progress and achieve an enviable record of development

We live in a competitive world, where different socio-economic systems try to portray themselves in the best light while portraying other competitors in bad light in order to appear as the ideal system. The Western nations portray the socialist system as an "evil, Godless, authoritarian system", while the socialist nations portray the 'Western capitalist nations, as "insensitive, exploitative imperialistic nations led by oligarchies". In spite of this war of ideas, each system has succeeded in building sufficient confidence into its people as we have seen above. Their social scientists have played the roles of strengthening the confidence of their citizenry by providing them information which extols their system, and denigrates other systems m competition with them. The Western nations in their efforts to dominate the world have, of course mounted ideological assault and propaganda against the values, institutions and world' views of those nations including Nigeria. Partly because of the weakness of our system we have fallen victim of this onslaught, to the extent that we have now come to have a very negative image of ourselves and our socio-economic system.

It is my perception that Nigerian social scientists have so far failed in the necessary task of providing information and analysis that would help to p or-tray Nigeria in a more positive light Our self-criticism has been carried to a point that I now consider it as destructive. I do not see how a nation that has no confidence in itself can motivate its citizens to any significant height of achievements. The lack of a positive image of Nigeria, would obviously lead citizens by and large not to have any strong commitment to the nation. Actions of individuals would become largely and excessively selfinterested. It is this type of attitude that encourages the view of Nigeria, as a "no man's business", with no hope, and therefore individuals are encouraged to extract as much as they can from the system before it collapses.

It is in this regard that I see an important role for what I call a positive Social Science in Nigeria. A positive social science in Nigeria which must 


\section{Annals of the Social Science Council of Nigeria}

have a much greater weight in the rest of the $1980 \mathrm{~s}$ and beyond, would be oriented towards research that would generate result and lead to a better image for Nigeria. The positive social science, of course, implies the active involvement of such of the social science disciplines. The results of such positive social scientific research, would need to be actively transmitted to society at large, through a programme of active public education aimed at strengthening^ ${ }^{\wedge}$ self-confidence in Nigerians while preparing them to face unresolved problems with a strong determination to succeed. We need to highlight more strongly what we have achieved and the strength of our system, while not*losing sight of what remains to be achieved. Such an approach would provide a more balanced information which we can feed to our citizenry. A nation, just like an individual, which has 'some record of achievement, knows that it can build on its past record, and can be motivated to greater heights of achievements, whereas if the image is one of hopelessness, then clearly very little is likely to be achieved.

The implications of this approach to the Social Sciences in Nigeria are extensive. Time constraint does not permit us to go into any detailed illustration. Some of the supposed negative aspects of the Nigerian system can in fact be turned around into a positive dimension. Take for example, the issue of load-shedding by NEPA. Most people see this phenomenon as extremely unfortunate and bad. However, careful analysis would show that it is simply not possible at our stage of development to provide uninterrupted and steady electricity supply to all possible users, and meet other socio-economic demands. This is possible only at much higher levels of development The choices open in a situation where uninterrupted electricity supply to all users is impossible, are essentially two. One option is to provide steady and uninterrupted electricity for the few that can afford it at economic or more than economic costs, while the second option is to ration the limited supply of electricity to a larger number of consumers, implying, of course, that electricity could not be available uninterrupted to those supplied. Which of those options is better? It depends on your value-system. If you believe in the good of the greatest number you would conclude that the load-shedding approach is better. Most fairminded people believe in the good of the greatest number, and therefore the Nigerian system of load-shedding of electricity would in the present circumstances be such a good thing of which we can be proud rather than be ashamed. However, to see the positive side is not to deny that a problem remains. The problem in this case is how to reduce the incidence and duration of load shedding over time, until we reach the desired goal of continuous and uninterrupted electricity supply for all. Further examples of this type of analysis could be readily multiplied. 
Strengthening the Social Sciences in Nigeria

Part of the reason why the Social Sciences in Nigeria may have been largely negative in approach so far, is the relatively weak state of the social sciences in Nigeria. The weakness of the social sciences may be attributed to the paucity of competent social scientists engaged in teaching and research in Nigeria. While the scarcity of competent social scientists engaged in research and 'training may be relatively less acute than that of other scientists and technologists, it is very obvious that the position of staffing of the teaching departments in the social sciences in our Universities is far from satisfactory. The staffing situation in our national research institutes in the Social Sciences, is even worse than that of the Universities. With the limited supply of social scientists it has not been possible to address the wide range of issues that call for urgent attention, such as the positive aspects of the socio-economic system vis-a-vis the negative aspects.

The weakness of the social sciences as reflected in the paucity of competent social scientists is further seriously exacerbated by the gross inadequacy of funds for social science research. The problem of inadequacy of research funds is partly a general problem of inadequate funds for any kind of research. However, the problem of inadequacy may be more acute in the social sciences than for other sciences as we shall see presently. The problem of inadequacy of funds has several dimensions. Obviously with limited funds, only a few problems can be addressed, thereby leading to an inadequate information base for policy decisions, with the result that very costly mistakes can be made The inadequacy of funds also leads to the fact that Nigerian researchers become captives of foreign organisations which have funds for research, objectives of which are not related to Nigerian's interests. Nigerian scholars in their quest to accumulate a satisfactory record of publication for promotion purposes, thus find themselves working for foreign interests, with the result that much of their research becomes irrelevant to national development objectives. We therefore have a de facto situation or brain-drain even when the scholars are resident in Nigeria.

It is for this reason that the nation must face up to the issue of providing more funds for research in the Universities and the national research institutes. Economic analysis has shown that technological change, which is largely the result of basic and applied research, contributes far more to economic growth than investment, in capital and natural resources. Further analysis also shows that the resource that is allocated to research and development in developed countries is as much as $21 \%$ of their GNP. If it is assumed that about $20 \%$ of all research is in the social sciences, then about $1 / 2 \%$ of GNP should be committed to social science basic and applied research. However, available evidence in Nigeria shows that the resource that $4 \mathrm{~s}$ committed to research in the social sciences is virtually insignificant Until 1982, The Nigerian Institute of Social and Economic Research (NISER), the national 
Institute charged with social and economic research did not have any annual or regular research fund The research fund likely to be available for NISER in 1984 will be only N250,000 for a full-time research staff of some 70 professional staff. The Nigerian Institute of International Affairs has specific research fund and the same situation obtains at the National Institute of Policy and Strategic Studies. The Ministry of Science and Technology does not conveive of its mission as including support of basic research in the Social Sciences, although all national agencies for supporting science in other countries always make provision for the social sciences. In the entire University system funds available for social research is not likely to exceed $\mathrm{Nl}$ million, even if it can approach $\mathrm{Nl}$ million. In the Ministry of National Planning, the funds available for studies in the National Planning office and the Federal Office of Statistics in the recent past have been less than N2 million. All told, the total funds available for research in the social sciences, a total sum of N187 million, should have been spent in 1983 compared to less than the N4 million actually spent in Nigeria. This implies that our level of effort is only about $2 \%$ of what it ought to be. This is a woeful performance and calls for an immediate corrective action, if the social sciences are to play the critical role which they must play if this country is to have any meaningful development.

\section{Conclusion}

The leadership role in any society is largely played by social scientists. Their ideas, values and knowledge are largely derived from the body of knowledge accumulated by social scientists. Social scientists therefore play a critical rde in any society, and for a developing country like Nigeria, that role may be even more critical. We have argued in this address that there is need for a more positive social science in Nigeria which would strike a better balance between highlighting the achievements and strengths of our socio-economic system as against its weaknesses which, of course, must be eliminated through committed action as soon as possible. We have also highlighted the scarcity of qualified manpower in the social sciences and demonstrated that the national effort in support of social science research so far has been woeful No meaningful development can take place in the country if the past trends are allowed to continue. We hope the Honourable Minister of Education, Science and Technology will see to it that the Science and Technology Department of his Ministry devotes at least 20\% of the funds it has to support scientific research to the Social Sciences. Such funds may be best disbursed through the Social Science Council of Nigeria which, as we have shown, has among its objectives, the identification of research priorities in the social Sciences and the support of innovative and indigenous approaches to Social Science research, which is relevant to the goals of national development 


\section{REFERENCES}

1. See for example L. D. St ifel R- K- Davidson and J. S. Coleman fete.) Social Sciences and Public Priorities for National Development, Ibadan 1981; A.O. Sanda (ed.) Social Science and Social Policy in Nigeria (NISER, Ibadan 1981), and

V.P. Diejomaoh, "Nigeria-Social Science Research Priorities for Development". Africa Spectrum (African Institute, Hamburg'1983).

2. V.P. 'Djejomaoh, "Higher Education and Manpower Development" paper presented at the Annual Corfference of the Committee of Vice-Chancellors! Feb. 1982.

3. V.P. Diejomaoh, Financing Development .Expenditure: Lessons front Nigerian experience (Ph.D. Thesis Harvard 1968).

4. V. P. ,Diejomaoh, "The Economics of the Nigeria Civil War,"in J. Okpaku (Ed.) Nigeria-Biafra Dilemma of Nationhood (Greenwood Press, Conn. 1982).

5. V.P. Diejomaoh, 'Planning for Nigerian Manpower Requirements. Muxas and Realities in V.P. Diejomaoh; E.F. Ojo and C.C. Okoye (Eds.) The Manpower Constraints on Nigerian Economic Development. National Manpower Board (forthcoming). Also see V. P. Diejomaoh, "Nigerian Social Science Research Priorities for Development". 